
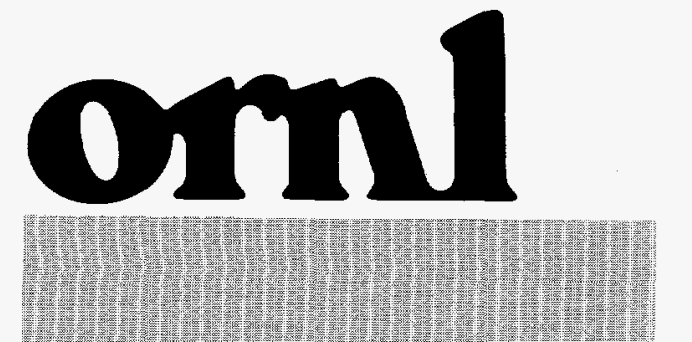

OAK RIDGE NATIONAL LABORATORY
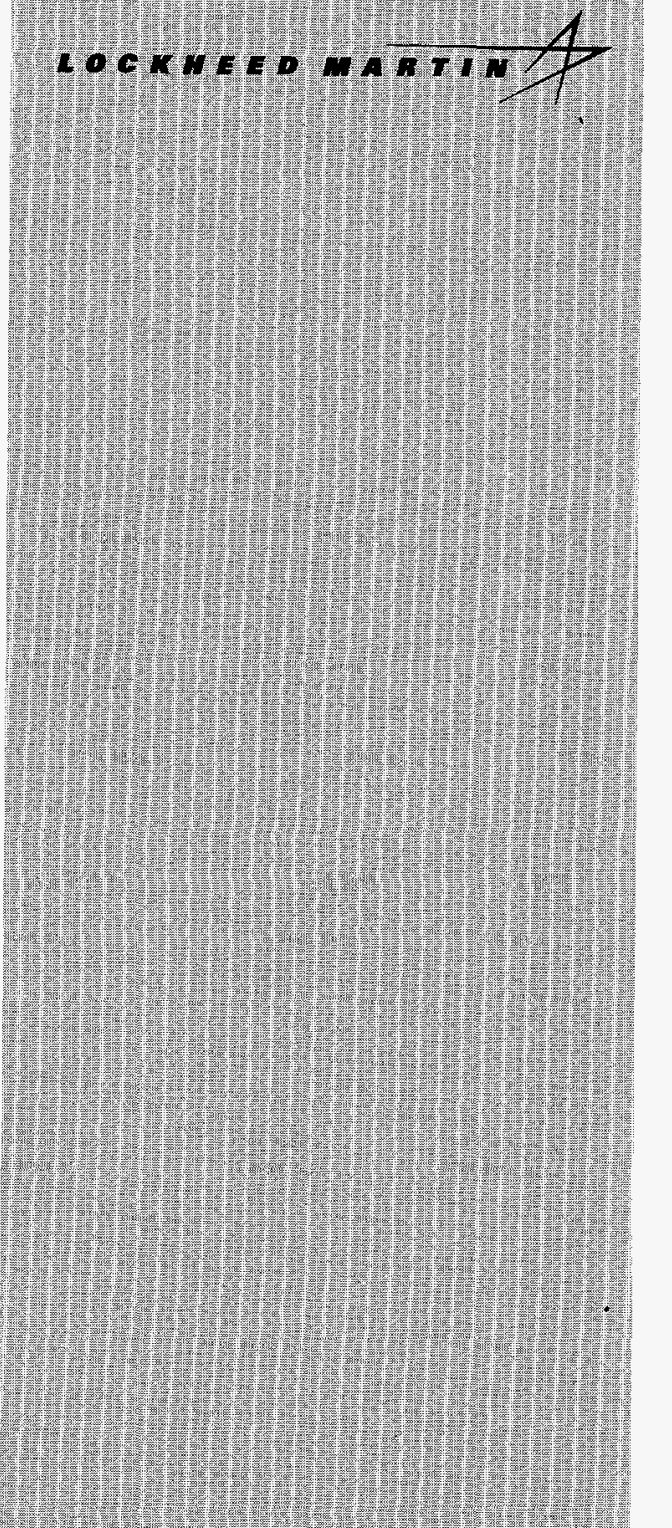

YANAGE ANO OPERATED GY LOCKHEED UARIN ENERCY RESEARCH CORPORATION FORTHEUHTEO STATES DEPARTIETT OF ENEREY

\section{PECETVDO OCT 051998 OSTI Gallium-Clad Phase III and Phase IV Tasks \\ (Canceled Prior to Completion)}

\author{
R.N. Morris
}

August 1998

Fissile Materials Disposition Program
Notice

This report was prepared as an account of work sponsored by an agency of the United States Government. Neither the United States Government nor any agency thereof, or any of their employees, makes any warranty, expressed or implied, or assumes any legal liability or responsibility for any third party's use or the results of such use, of any information, apparatus, product or process disclosed in this report, or represents that its use by such third party would not infringe privately owned rights.

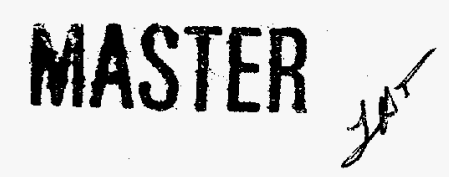

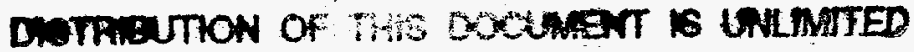




\section{DISCLAIMER}

This report was prepared as an account of work sponsored by an agency of the United States Government. Neither the United States Government nor any agency thereof, nor any of their employees, makes any wartanty, express or implied, or assumes any legal liability or responsibility for the accuracy, completeness, or usefulness of any information, apparatus, product, or process disclosed, or represents that its use would not infringe privately owned rights. Reference herein to any specific commercial product, process, or service by trade name, trademark, manufacturer, or otherwise does not necessarily constitute or imply its endorsement, recommendation, or favoring by the United States Government or any agency thereof. The views and opinions of authors expressed herein do not necessarily state or reflect those of the United States Government or any agency thereof. 


\section{DISCLAIMER}

Portions of this document may be illegible in electronic image products. Images are produced from the best available original document. 


\title{
Results of the Gallium-Clad Phase III and Phase IV Tasks (Canceled Prior to Completion)
}

\author{
R.N. Morris \\ Oak Ridge National Laboratory
}

August 1998

Prepared by the OAK RIDGE NATIONAL LABORATORY, Oak Ridge, Tennessee 37831, managed by LOCKHEED MARTIN ENERGY RESEARCH CORPORATION for the U.S. DEPARTMENT OF ENERGY under Contract DE-ACO5-96OR22464. 


\section{CONTENTS}

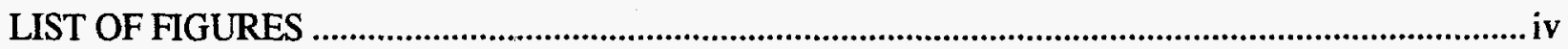

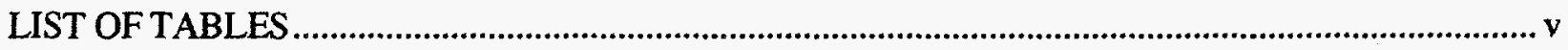

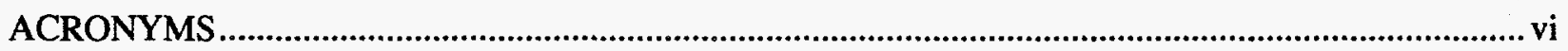

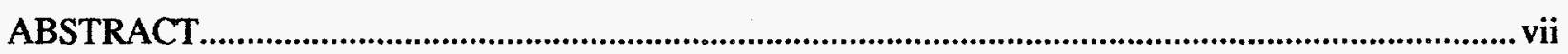

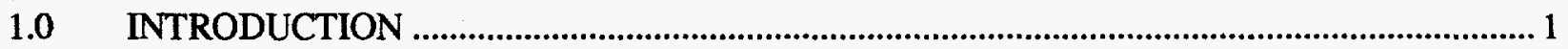

2. 0 THE RATIONALE FOR PHASES III AND IV ....................................................................

2.1 PHASE III AND IV PLANNED EXAMINATIONS ......................................................... 4

3.0 TEST APPARATUS HISTORY FOR THE PHASE III AND IV TESTS ......................................6

3.1 TEST APPARATUS DIFFICULTIES .......................................................................

4.0 RODLET DESIGN AND PELLET FABRICATION ……..........................................................

4.1 DOE CONCERNS ABOUT TASK DELAYS .................................................................

4.2 RODLET PROBLEMS AND TASK CANCELLATION …….......................................... 11

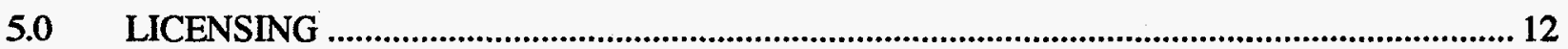

5.1 TVA MEETING........................................................................................................ 12

5.2 LICENSING APPROACH................................................................................... 13

6. 0 PLANNING FOR GALLIUM-CLAD FUTURE TASKS.................................................... 15

6.1 LOSS OF COOLANT ACCIDENTS ....................................................................15

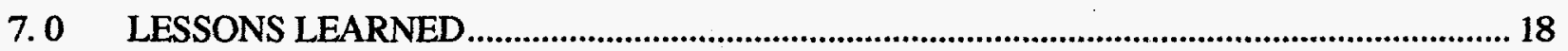

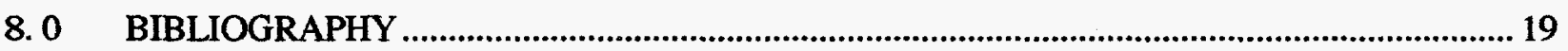

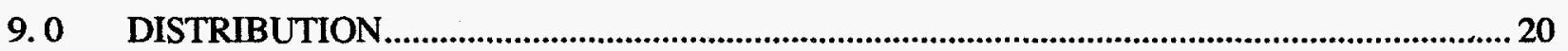




\section{LIST OF FIGURES}

FIGURE

PAGE

1. CONCEPTUAL DESIGN OF PHASE III AND IV CENTRALLY HEATED

RODLET. THE HEATER SIMULATES THE NUCLEAR HEAT PRODUCTION

2. SCHEMATIC OF THE PHASE III TEST APPARATUS. THE APPARATUS

IS AIR COOLED WITH LIQUID METAL CONVECTIVE FLOWS

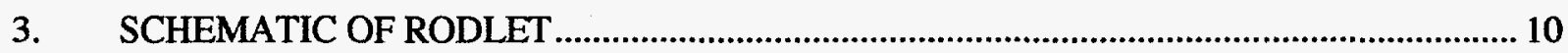

4. ZIRCALOY STEAM AND FUEL REACTIONS THAT OCCUR UNDER LOCA CONDITIONS 


\section{LIST OF TABLES}

\section{TABLE}

PAGE

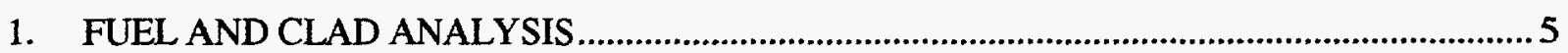

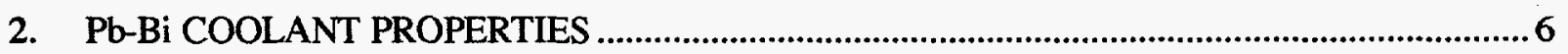




\section{ACRONYMS}

FMDP

MOX

LWR

LANL

DBA

ORNL

MXRF

CNAA

TAMUNSC

ANRCP

NRC

TVA

LEU

HEU

QA

QC

SAR

LTR

SRP

PRA

GDC

LOCA
Fissile Materials Disposition Program

Mixed Oxide

Light Water Reactor

Los Alamos National Laboratory

Design Basis Accident

Oak Ridge National Laboratory

Micro X-Ray Fluorescence

Comparative Neutron Activation Analysis

Texas A\&M University Nuclear Science Center

Amarillo National Resource Center for Plutonium.

Nuclear Regulatory Commission

Tennessee Valley Authority

Low Enriched Uranium

High Enriched Uranium

Quality Assurance

Quality Control

Safety Analysis Report

Licensing Topical Report

Standard Review Plan

Probabilistic Risk Assessment

General Design Criterion

Loss of Coolant Accident 


\begin{abstract}
This report summarizes the results of the Gallium-Clad interactions Phase III and IV tasks. Both tasks were to involve examining the out-of-pile stability of residual gallium in short fuel rods with an imposed thermal gradient. The thermal environment was to be created by an electrical heater in the center of the fuel rod and coolant flow on the rod outer cladding. Both tasks were canceled due to difficulties with fuel pellet fabrication, delays in the preparation of the test apparatus, and changes in the Fissile Materials Disposition Program budget.
\end{abstract}




\subsection{INTRODUCTION}

The Fissile Materials Disposition Program (FMDP) is investigating the use of weapons grade plutonium in mixed oxide (MOX) fuel for light-water reactors (LWR). Commercial MOX fuel has been successfully used in overseas reactors for many years; however, weapons derived fuel may differ from the commercial fuels in two ways. First, the isotopics of the fuel is different. Weapons derived fuel will contain greater amounts of ${ }^{239} \mathrm{Pu}$ and smaller amounts of the higher plutonium isotopes. Second, the weapons grade material many contain small amounts of gallium as an impurity. A concern exists that the gallium may migrate out of the fuel, react with and weaken the clad, and thereby promote loss of fuel pin integrity. The Gallium-Clad interactions task was initiated to address this concern.

Currently, the FMDP intends to remove the majority of the gallium during the plutonia powder conditioning prior to fuel fabrication. Investigations of powder conditioning and gallium evolution during fuel fabrication are being conducted by Los Alamos National Laboratory (LANL). A special thermal dry process has been proposed for gallium removal prior to fuel fabrication, however, this removal technique is not completely effective. It is probable that residual gallium will be carried through fuel fabrication into the finished fuel. Therefore, it is important to understand the potential cladding interactions and the available safety margins with respect to fuel gallium concentration for licensing and safe reactor operation. As the program has progressed the amount of gallium expected to be present in the fuel has significantly decreased. Originally, the gallium levels were expected to be as high as several hundred ppm in the sintered fuel. Currently, the initial gallium in the plutonium is expected to be roughly $100 \mathrm{ppm}$ gallium in the thermally treated $\mathrm{PuO}_{2}$, and about 1 to $10 \mathrm{ppm}$ gallium in the final MOX fuel after blending with uranium and sintering.

Even with these low levels of gallium, the damage problem cannot be quickly dismissed because small amounts of impurities (hydrogen) and fission products (iodine) have caused clad problems in the past. In addition, the current LWR fuel rod failure fraction is on the order of a few failures per million fuel rods. Thus, even a minor potential for problems is cause for investigation.

To address the gallium issue, a multiphase experimental program was undertaken that exposed cladding materials to gallium in various physical forms, under varying concentrations, and thermal conditions. The early phases, Phases I and II, of the program involved exposing clad samples to gallium metal or gallium oxide and will be run to completion. The later phases, Phase III and IV, were to expose both surrogate $\mathrm{UO}_{2} / \mathrm{CeO}_{2} / \mathrm{Ga}_{2} \mathrm{O}_{3}$ (Phase III) and MOX (Phase IV) fuel pellets to clad materials under conditions more typical of the reactor thermal environment. Both Phases III and IV have been canceled because of funding cutbacks, experimental difficulties, and schedule delays. A problem common to both was the difficulty in producing a special annular test pellet with relatively high levels of gallium. The majority of the gallium left the pellet during the sintering process and attempts to control the gallium level by varying the sintering environment were not successful. A possible extension of the gallium-clad effort was in the early planning stages and involved examining the types of tests necessary for Design Basis Accident (DBA) conditions. This effort was also discontinued pending the outcome of additional DOE guidance.

A great deal of work on gallium had already been performed by ORNL for the FMDP on the gallium issue prior to the order to end the program: Assessment of Gallium in $(\mathrm{U}, \mathrm{Pu}) \mathrm{O}_{2} \mathrm{LWR}$ Fuels, Terrence B. Lindemer, July 29, 1995; Potential Effects of Gallium on Cladding Materials, ORNL/TM-13504, D F. Wilson, et. al.; Interactions of Zircaloy Cladding with Gallium 1997 Status, ORNLTM-13505, D.F. Wilson, et. al.; and Interaction of Zircaloy Cladding with Gallium: 1998 MidYear Status, ORNL/TM13625, D.F. Wilson, et. al. In addition, relevant material has been presented at meetings and included in 
monthly reports. A final report on the Phase I and II work is due in September 1998, therefore, results of these tasks will not be covered in detail in this document.

Current out-of-reactor experimental evidence indicates that trace amounts of gallium in the MOX fuel will not present a serious clad corrosion problem. The gallium appears to be quickly tied up in intermetallic compounds, and trace amounts of gallium have not been found to cause problems other than generalized corrosion that is limited by the very small amounts of material available. At the present time, irradiation testing of the fuel and clad system is underway and information should become available in late 1998. 


\section{0 THE RATIONALE FOR PHASES III AND IV}

While Phases I and II exposed cladding to various gallium concentrations and temperatures, they were essentially isothermal tests. These tests were essential in developing an understanding of the expected material reactions that could occur. However, these tests could not provide information on gallium behavior or transport in the presence of a thermal gradient as would be typical in fuel during normal operation. In addition, the tests were run using liquid metal and powdered gallium oxide, forms that were quite different than sintered fuel. To provide a more realistic test environment, an experiment composed of centrally heated pellets contained in a cooled fuel clad, a "rodlet", was proposed as an out-of-reactor approximation to the fuel thermal environment, see Figure 1. The first of this series of experiments, Phase III was to use surrogate pellets made from depleted uranium and cerium as a substitute for plutonium. The second set of experiments, Phase IV, was to use actual MOX fuel pellets. Phase III was seen as a inexpensive way to evaluate the experimental conditions and apparatus, while Phase IV would use the actual MOX rodlets in a glove box or hot cell environment.

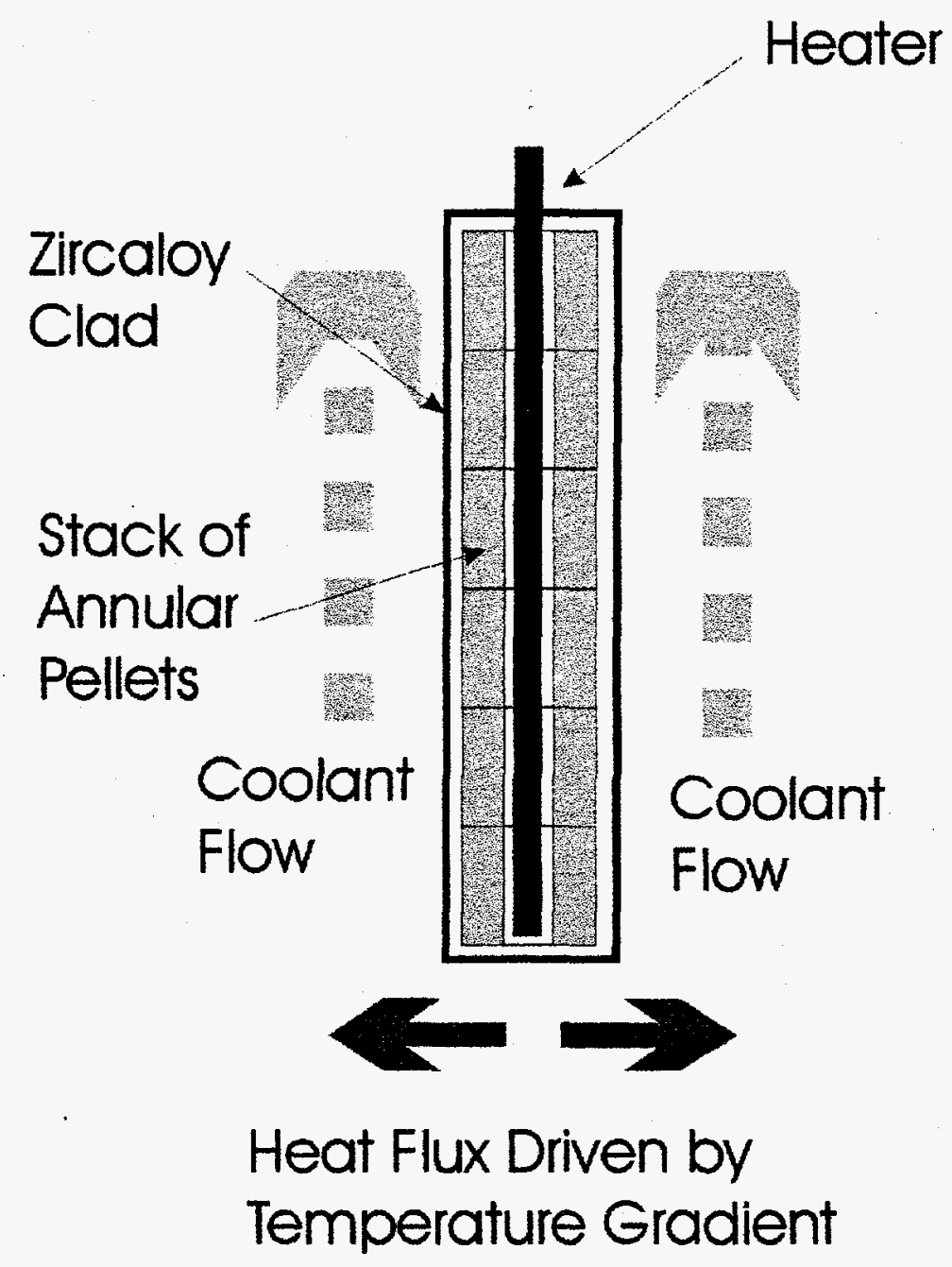

Figure 1. Conceptual design of Phase III and IV centrally heated rodlet.

The heater simulates the nuclear heat production. 
Even though the thermal environment of a fuel rod was approximated by these proposed experiments, both Phases had physical and chemical differences from the reactor environment beyond radiation. The tests would use fuel that contained no representative fission products so any chemical interactions that fostered or hindered the movement of gallium would not be present. Second, no attempt was made to simulate the surface contact that occurs when fuel swells and contacts the clad. This is a possible shortcoming because gaps between the fuel and clad limit material transport to gas phase transport and there are known reactions between zircaloy and fuel materials in tight contact, albeit at higher temperatures. Both of these issues were not addressed because of their complexity. Even so, the tests were seen as a useful step beyond the Phase I and II work and were part of the process of moving toward more prototypic testing. The irradiation experiments, now underway in the Advanced Test Reactor, were seen as addressing the fission product and gap issue at the lower gallium concentration ranges.

Two different gallium levels and three exposure times were selected for testing based on the need to collect data and meet a schedule that would provide information to the program prior to the selection of the consortium in the Fall of 1998. Because it was unknown what gallium levels could be achieved in the pellets, the program test plan simply specified that "high" and "low" gallium level pellets be produced. At each exposure time, 1000, 3000, and 5000 hours, a pair, one high and one low gallium, of specimens were to be removed from the test apparatus for examination.

\subsection{PHASE III \& IV PLANNED EXAMINATIONS}

After heating, the post test examination (at ORNL) of the rodlets was to focus on the distribution of the gallium. The examination was to search for evidence of gallium transport across the pellet and into the clad, wall thinning, grain boundary penetration, and any other notable changes in the clad material. The morphology, microstructure, and gallium content of the surrogate fuel pellets was also to be evaluated and compared to the starting material. The primary interest was in the gallium that leaves the pellet and deposits on or enters into the cladding material. Table 1 is a general outline of the types of examinations that were planned for each phase. An important program goal was to identify time and cost effective analytic techniques used by or developed by other FMDP programs for determining gallium profiles that could be used for this task and future tasks associated with irradiated material. To date, no truly convenient methods have been developed for determining gallium profiles in the fuel and clad. The current methods rely on wet chemistry, neutron activation, or mass spectrometry, all of which require tedious sample preparation to obtain gallium profile information.

Initially, the gallium analysis was proposed to begin by the analysis of samples in a scanning electron microscope to determine the disposition of the gallium; it could be evenly distributed throughout the sample, segregated at the surface of the pellet, or concentrated in grain boundaries. Once this information was known, the feasibility of using other techniques such as micro-X-ray fluorescence (MXRF) could be evaluated if the technique was proven by other projects. Radial gallium scans would be most easily done using MXRF if it was determined to be possible and suitable. Measurements using comparative neutron activation analysis (CNAA) could have been attempted but would have required that the pellet or clad section be cut up. CNAA was the back up method as it has been used before by other programs to determine trace gallium levels.

Rapid and routine detection of trace gallium levels and gallium concentration profiles was an issue that was never resolved to the satisfaction of the personnel responsible for doing the post test examination work. Currently LANL is working on gallium analytic methods. Resolution of this problem is advised before attempting any more tests that require gallium profile information. 
TABLE 1

Fuel and Clad Analysis

\begin{tabular}{|l|c|c|}
\hline \multicolumn{1}{|c|}{$\begin{array}{c}\text { Each Phase would have examined } 6 \text { rodlets in three pairs: } 1000 \\
\text { Archives will be examined as relevant. }\end{array}$} \\
\multicolumn{1}{|c|}{ Examination } & $\begin{array}{c}\text { Approximate } \\
\text { Number per } \\
\text { Rodlet }\end{array}$ & $\begin{array}{c}\text { Estimated } \\
\text { Total } \\
\text { Number }\end{array}$ \\
\hline \begin{tabular}{l|c|}
\hline \\
Rodlet Photo-Visual and Dimensional Inspection
\end{tabular} & 1 & 6 \\
\hline $\begin{array}{l}\text { Rodlet Segment Photo-Visual Inspection } \\
\text { (Rodlets and/or archives as relevant) }\end{array}$ & 2 & 12 \\
\hline $\begin{array}{l}\text { Rodlet Segment Ceramography/Metallography } \\
\text { (Rodlet and/or archives as relevant) }\end{array}$ & 2 & 12 \\
\hline Selected Clad Specimen Hardness Test (if applicable) & 1 & 6 \\
\hline Clad Segment Elemental Mapping ( Tentative) & 1 & 6 \\
\hline Pellet Elemental Mapping ( Tentative) & 1 & 6 \\
\hline
\end{tabular}




\section{0 TEST APPARATUS HISTORY FOR THE PHASE III AND IV TESTS}

Using water as a coolant for these tasks would require the design and construction of a high temperature pressurized (greater that $2000 \mathrm{psig}$ ) cooling loop with a complicated pumping system. A combination gas gap/water jacket is a possible alternative offering low pressure operation, but the small gaps, high flow rates, and tight mechanical tolerances made a system of this nature initially less attractive. However, this concept was later reexamined for Phase IV when it became clear that the proposed Phase III apparatus would be difficult to incorporate into a hot cell environment.

The Texas A\&M University Nuclear Science Center (TAMUNSC) was given the task of designing and constructing the test apparatus to be used for the Phase III tests. They were selected because of the possible leveraging of funding they received through Amarillo National Resource Center for Plutonium (ANRCP).

TAMUNSC personnel selected liquid metal cooling to avoid a high temperature pressurized system and selected natural convection based on air cooling as the circulation method to avoid pumps. Lead-Bismuth ( $\mathrm{Pb}-\mathrm{Bi})$ Eutectic $(44.5 \mathrm{wt}-\% \mathrm{~Pb}, 55.5 \mathrm{wt}-\% \mathrm{Bi})$ was selected as the coolant because of its relative chemical inertness and low melting temperature. Table 2 summarizes the properties of the selected $\mathrm{Pb}-\mathrm{Bi}$ eutectic alloy.

TABLE 2

$\mathrm{Pb}-\mathrm{Bi}$ Coolant Properties

\begin{tabular}{|c|c|c|c|c|c|}
\hline $\begin{array}{c}\text { Calculated } \\
\text { Atomic } \\
\text { Mass }\end{array}$ & $\begin{array}{c}\text { Melting } \\
\text { Point } \\
\left({ }^{\circ} \mathrm{C}\right)\end{array}$ & $\begin{array}{c}\text { Boiling } \\
\text { Point } \\
\left({ }^{\circ} \mathrm{C}\right)\end{array}$ & $\begin{array}{c}\text { Density at } \\
400^{\circ} \mathrm{C} \\
(\mathrm{gm} / \mathrm{cc})\end{array}$ & $\begin{array}{c}\text { Specific Heat } \\
144-358^{\circ} \mathrm{C} \\
\left(\mathrm{cal} / \mathrm{g}-{ }^{\circ} \mathrm{C}\right)\end{array}$ & $\begin{array}{c}\text { Thermal Conductivity } \\
\text { at } 300^{\circ} \mathrm{C} \\
\left(\mathrm{cal} / \mathrm{sec}-\mathrm{cm}-{ }^{\circ} \mathrm{C}\right)\end{array}$ \\
\hline 208 & 125 & 1670 & 10.19 & 0.035 & 0.026 \\
\hline
\end{tabular}

The apparatus for conducting the test was basically a tank containing the liquid metal with cooling fins on the outside for heat rejection, and an internal flow guide section surrounding the heated rodlet group. See Figure 2 for a schematic of the apparatus. Considerations for the cooling system concept were based on simplicity and low cost. Using the natural circulation of the coolant avoided designing a mechanical pumping system. Calculations made by TAMUNSC showed that the temperatures produced from a small diameter heater in the surrogate annular pellet stack would approximately match the thermal gradient in operating fuel pellets.

To drive the thermal gradient across the pellets and provide the source for thermally driven gallium diffusion, the rodlet (see the next section) contained a small diameter $(\sim 0.18$ inch OD) electric heater that was to operate in the temperature range of 500 to $1000^{\circ} \mathrm{C}$ with a linear power of approximately 15.7 $\mathrm{kW} / \mathrm{m}$. The experiment was to be configured to produce a nominal clad-pellet interface temperature of $400^{\circ} \mathrm{C}$.

System components were fabricated from ferritic steel which has good corrosion resistance to $\mathrm{Pb}-\mathrm{Bi}$. The rodlets were to be immersed directly into the $\mathrm{Pb}$ - $\mathrm{Bi}$ coolant and held in place by the cover over the bath. The thermal and hydraulic parameters of the full sized system have been calculated by TAMUNSC and indicate that the designed system would be able to remove the $20-30 \mathrm{~kW}$ of heat generated. 


\section{Top View}

Temperature gradient is maintained by central heating and convective coolant flow

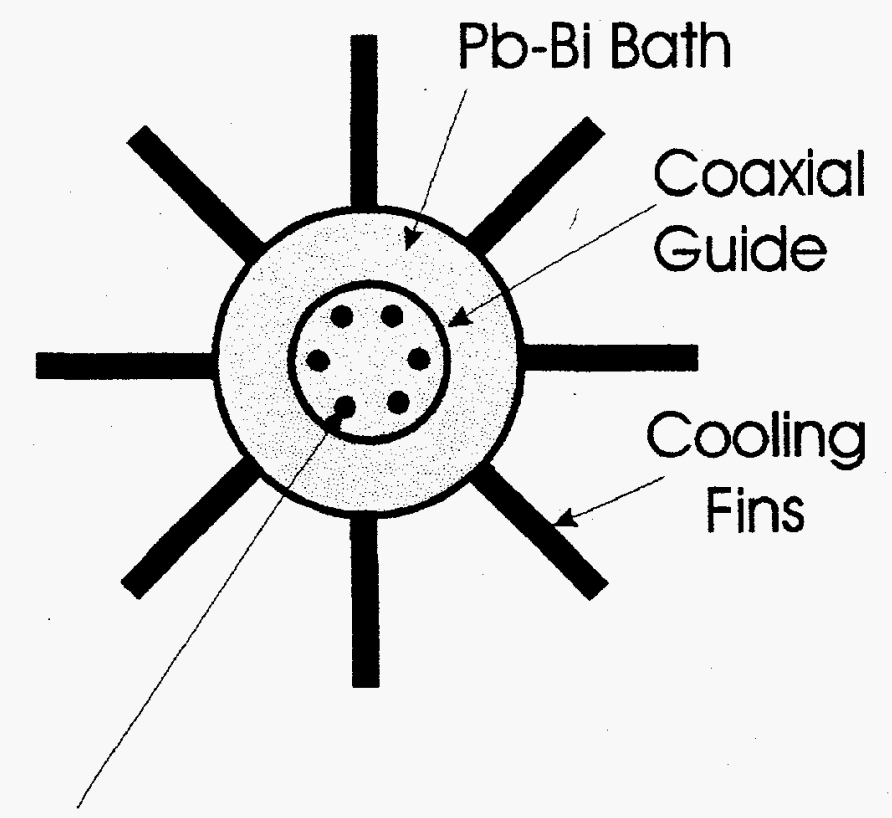

Heated Rodlets

Air Flow

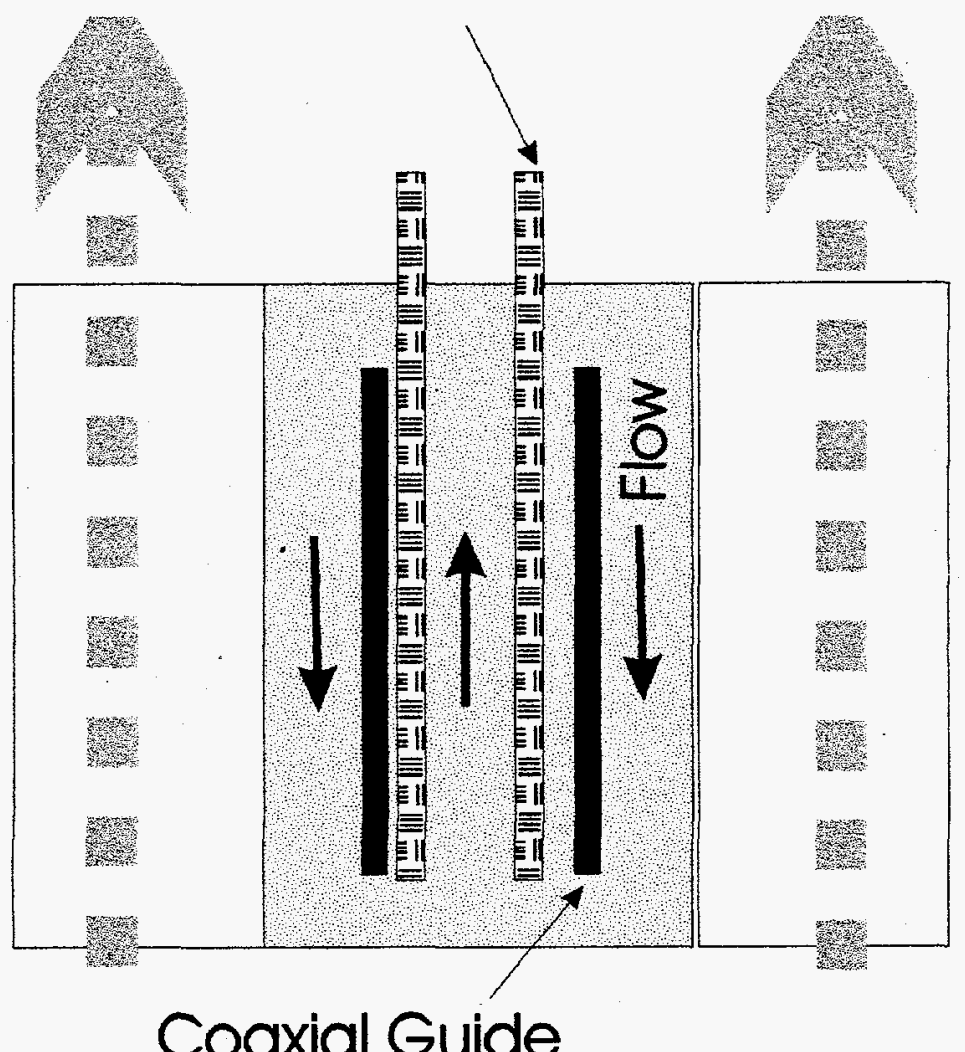

Side View

Figure 2. Schematic of the Phase III test apparatus.

The apparatus is air cooled with liquid metal convective flows. 
The heated sections of the rodlets were to be placed low in the flow guide for maximum thermal driving head (only the bottom six inches of the rodlets were to be heated - see the next section on the rodlets). The coolant flows up and out of the coaxial guide due to natural convection, down along the cooled side of the apparatus, and reenters the coaxial flow guide to complete the circuit. The efficiency of the aircooling determines the steady-state coolant operating temperature. Fans would be cycled on and off to control the cooling rate. Modeling and testing were to be used to map out the thermal behavior of the test apparatus. An approximate half scale model of the apparatus was constructed with a different heating source and much less fin area. The results of the model testing were encouraging, but no formal quantitative reports on the scaled apparatus were prepared by TAMUNSC for the FMDP.

Formal reporting on the thermal behavior of the Phase III apparatus was not included in the FMDP (Phase III and IV) funding. Proceeding without this information was a technical risk. At the time the project was being planned it was assumed that the ANRCP funding would cover the basic testing and documentation, but this proved not to be the case. Informal experimental data presented by TAMUNSC on the subscale unit indicated that the test temperatures would be achieved by the full scale unit provided that the physical characteristics scaled up. The rodlet heater design was considered to be pushing the limits, but all other components were operating well within their capabilities. ORNL personnel visited TAMUNSC in December of 1997 and reviewed their facility and equipment. Progress was being made on the apparatus and control system, but general documentation was unavailable. TAMUNSC agreed to supply the operating procedures and drawings when the equipment had been completed and tested. The project then encountered technical problems and several delays and was canceled before this information could be compiled and supplied to the program.

\subsection{TEST APPARATUS DIFFICULTIES}

Both Phase III and Phase IV began running into difficulties in early 1998. At this point it became clear that the Phase III apparatus would not work well in the hot cell because of the need for a high air flow rate to remove the heat. Thus, it was not suitable for the Phase IV task as had been hoped for in the original planning. TAMUNSC had no responsibility for the Phase IV effort and the hot cell constraints could not be accommodated by them. At this point a new apparatus design effort for the Phase IV effort was undertaken using the gas gap and high water flow rate concept. The design appeared to be feasible and an engineering effort was undertaken. Shortly thereafter, the cost of making the special MOX annular pellets was found to be prohibitively expensive and entailed a long schedule. In early Spring of 1998 DOE canceled the Phase IV effort because of the cost and schedule issues.

Phase III ran into three problems at this point as well. First, institutional problems prevented a timely transfer of funds to TAMUNSC and generated contract problems with LANL which resulted in a delay until the problems were resolved. Second, pellet fabrication and gallium control proved to be much more difficult than expected. Finally, TAMUNSC ran into delays procuring and integrating all the required components for the test apparatus. 


\section{0 RODLET DESIGN AND PELLET FABRICATION}

The Phase III and IV rodlets were composed of a zircaloy cladding, annular pellets, an insulator, a central heater, and a top section that provided for electrical connections and a helium purge. A schematic of a typical rodlet is shown in Figure 3.

The sintered annular pellets of surrogate MOX fuel were manufactured by LANL. The surrogate fuel was composed of $95 \% \mathrm{UO}_{2}, 5 \% \mathrm{CeO}_{2}$, and whatever gallium remained after sintering. The annular pellets had an outside diameter of 0.310 inches and an inner diameter of $0.18 \mathrm{inch}$. The clad outside diameter was 0.382 inches and the inner diameter was 0.332 inches.

The rodlets were constructed of one of the vendor supplied clads that was also being used for the Phases I \& II testing. The original plan was to have two distinct and widely different sintered pellet gallium concentrations, such as (for example) 10 to $100 \mathrm{ppm}$ for the low gallium and 100 to $1000 \mathrm{ppm}$ gallium for the high gallium (the actual practical values were to be determined during the pellet fabrication task). This, along with the three heating times, would have resulted in a six-test matrix. At the completion of a heating interval a pair of rodlets, one high and one low gallium concentration would have been removed. The high gallium concentration rodlet would be examined for interactions. If no interactions were noted, the low gallium concentration rodlet would be put back into the apparatus for further heating. Thus, maximum use would be made of the rodlets.

This plan had to be modified in late Spring of 1998 when an analysis of the first batch of pellets revealed that both the low gallium and high gallium concentration sintered pellets had approximately the same gallium level, roughly $10 \mathrm{ppm}$, even though the presintering gallium levels were quite different. On the basis of these initial results it was clear that the gallium was being removed during the sintering process. Attempts were made to reduce the loss by process and sintering temperature changes, but significant modifications were not possible with the resources committed to the project. Differences were noted in the pellet microstructure, however. Because of the differences in the microstructure, the project plan was modified to refer to presintering levels of the gallium concentration in May 1998.

\subsection{DOE CONCERNS ABOUT TASK DELAYS}

A few weeks before the gallium analysis was completed (late March) on the first batch of test pellets, DOE had become concerned about the delays, fabrication problems, and program value of the Phase III effort. The following guidelines were established for the Phase III effort:

1. Analyze a surrogate pellet for its gallium content If there is only a very small amount of gallium in the pellet (of the same order as that in the irradiation tests) there is no point in doing the Phase III task as the irradiation experiment is already exposing pellets with trace gallium to a reactor environment and the Phase I and II work is examining specific mechanisms.

2. If the pellets are not fabricated and the rodlets prepared and ready for insertion in the test apparatus by the end of May, the Phase III task is to be canceled. The reason for cancellation would be the task's inability to meet the desired test schedule.

3. If the test apparatus is not up and running by the end of May with a test inserted and initiated then the Phase III activity is to be canceled. Again, the reason for the cancellation would be the task's inability to meet the desired test schedule. 


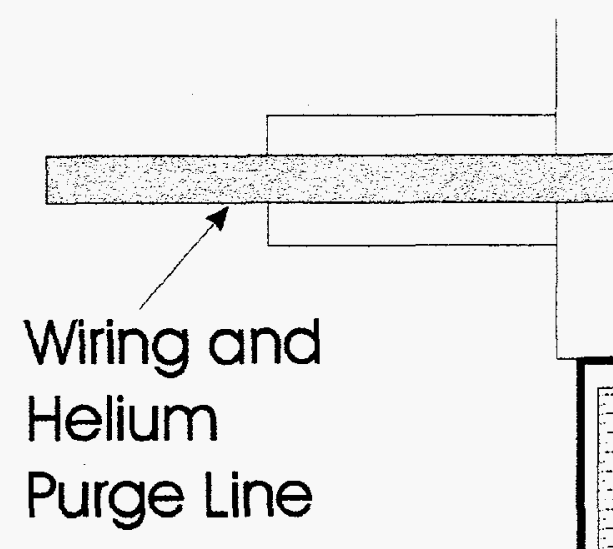

The as-built Rodlet had a pellet stack of only 4 inches and a gap at the top of the Rodlet between the alumina insulator and the top connector of 2 inches

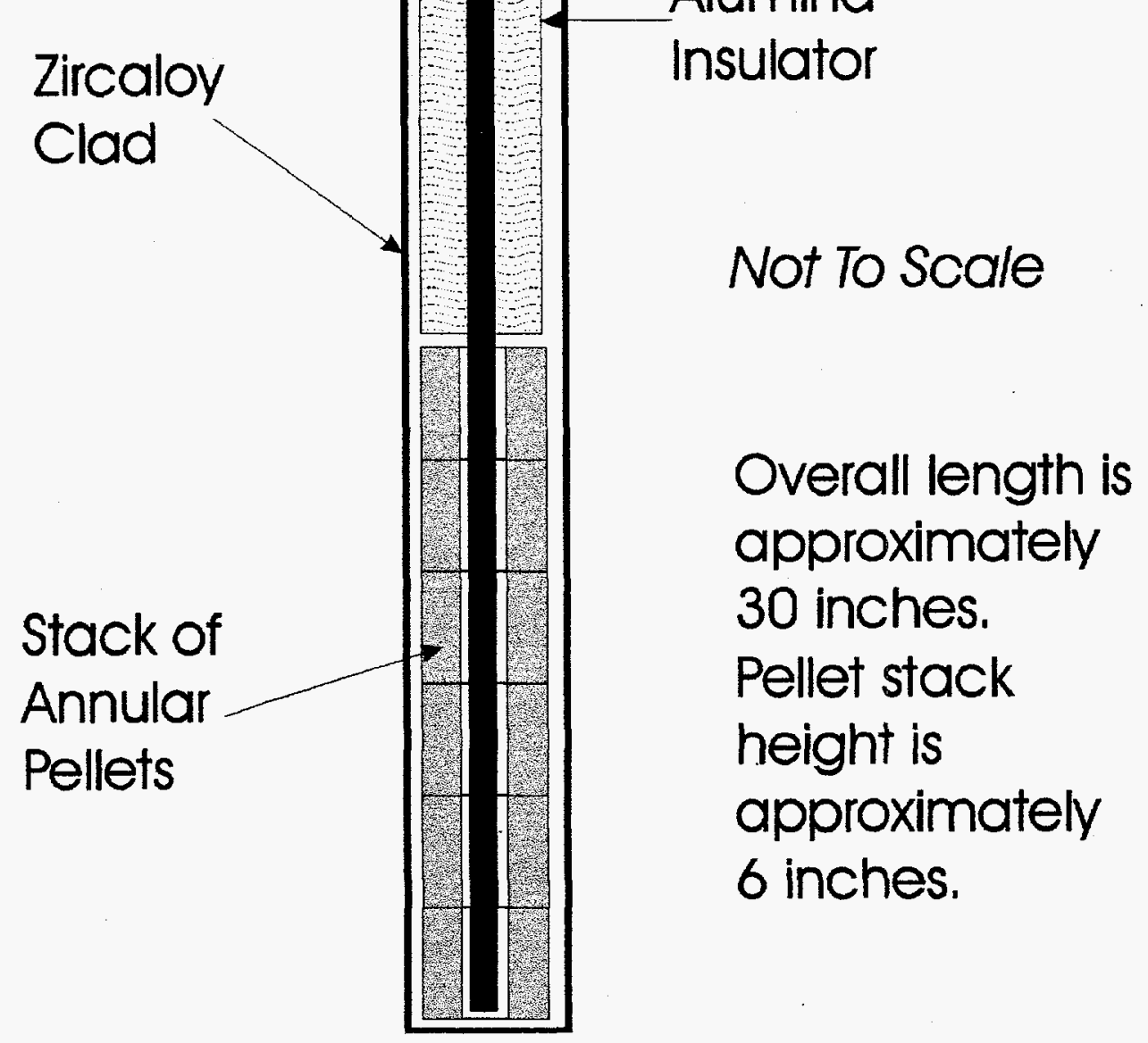

Figure 3. Schematic of rodlet. 
After the release of these guidelines, both LANL and TAMUNSC committed to meet them. However, delays in placing the contract with TAMUNSC and delays fabricating equipment put the project behind schedule. Also, as noted earlier, the gallium analysis of the pellets was not favorable to the task. LANL was also having problems with the pellet fabrication. The net result was that the May deadline was missed. DOE then decided to let the work proceed as long as no more money was committed to the task other than oversight. Preparations for post test analysis at ORNL were essentially stopped. A new date of late June was set for start up.

\subsection{RODLET PROBLEMS AND TASK CANCELLATION}

A major rodlet problem surfaced in June. The pellets had not survived the sintering intact and had cracked at several axial locations resulting in a batch of annular pellets of random lengths from about 0.1 to 0.4 inches. In addition, the pellet yield was smaller than anticipated. This resulted in a stack of pellets in each rodlet approximately 4 inches tall rather than 6 inches and composed of random length pellets with uneven faces. The alumina insulator that sat on top of the pellet stack was now about 2 inches too short with the gap being located at the top of the rodlet. This was acceptable because the top of the rodlet was not heated. Radiographs of the rodlets revealed that some of the rodlets had gaps in the pellet stacks which could be a source of potential problems. FMDP had concerns about the heat transfer properties of the rodlets and whether they would be suitable for the task..

Additional test apparatus problems at TAMUNSC pushed the start up date to late July. Concerns were being raised about the current value of the testing in light of the delays and technical problems. In mid July, DOE announced funding cutbacks for the FMDP program in general and terminated the GalliumClad task for fiscal year 1999. Since the Phase III task was so far behind schedule and suffering technical problems, a decision was made to terminate the task at the end of July 1998. The work was ordered stopped and close out costs were requested from TAMUNSC. 


\subsection{LICENSING}

In the Spring of 1998, ORNL examined the MOX fuel effort from a licensing point of view and put together the "Gallium Issues" report (Wichner and Morris). This document reviewed the NRC licensing guide (NUREG 0800, Standard Review Plan) and 10.CFR.50 and outlined how one might approach the entire MOX fuel licensing issue.

In addition to and in support of this licensing exercise, several ORNL personnel met with TVA personnel. The purpose of the meeting was to discuss TVA's experience with the NRC related to licensing of tritium-producing targets and off-spec LEU fuel assemblies and, through this discussion, gain an enhanced understanding of the scope of fuel qualification and licensing activities needed for the reactorbased plutonium disposition option of the FMDP.

\subsection{TVA MEETING}

The general tone of the TVA meeting was that a gradual step-by-step approach to licensing was best. The FMDP should plan to formally address all issues, even minor ones, to demonstrate the effort as being thorough and complete. Not all issues would require a long explanation, but the NRC would want to see some kind of proof or analysis to support the answers provided. Weak or uncertain answers would simply encourage the NRC to ask for more. The NRC expects the holders of reactor operating licenses to submit a license amendment request for significant operational changes and the program should not expect to rely on 10.CFR.50.59 (i.e., "no change" of significance) for projects of our nature (MOX). The 10.CFR.50.59 approach was taken by DOE during the initial phases of tritium-producing target activity and resulted in credibility concerns by the NRC and lost time in target deployment. A thorough approach was taken with the off-spec $\mathrm{HEU}$ material (high ${ }^{236} \mathrm{U}$ content) to avoid delays and concerns of this nature.

TVA recommended that the program (through the consortium) should be confident with its plan/results before going to the NRC. The "model" for deploying the MOX fuel assemblies (including all intermediate "test" steps) and the expected licensing activities should be clearly identified. The NRC will depend on the program/consortium for the adequacy of supporting analyses and testing; questioning should be expected, and any lack of confidence or completeness will be seen as a red flag. The program and consortium should be open and straightforward about any issues where additional information is needed and have plans for addressing these issues.

Plans should be made to educate the NRC on our intentions and methods so that they understand the overall MOX program and where it intends to go and why.

In general, the MOX fuel program will be a high visibility program. For this reason we should expect that the NRC will require more in the areas of licensing rather than less. The NRC will want to give the public a chance to comment and avoid any impression of favoritism to DOE. Thus, our arguments should be sound and complete - it is unlikely that we will get the benefit of the doubt.

Quality control (QC) and quality assurance (QA) are important issues for the program to think about. What is tested and what is put into the reactor must be, within the limits of practical testing, the same thing. This implies that whoever fabricates the fuel and builds the rods for the loop tests or lead assemblies must have an NRC-approved QA/QC program or be a qualified supplier for someone who does. Also, a clear line of responsibility must be established - who is in charge of what. In the FMDP case, this could mean that a vendor would have to qualify a national laboratory. In the tritium-producing target case, PNNL was qualified by Westinghouse as a supplier for the targets. This effort involved 
significant resources, and it was considered to be a major hurdle to cross in the target deployment activity.

In any event, QC/QA issues and assignment of formal responsibility for specific activities and/or components are important issues in the licensing process. In the MOX case, this consideration will be most important in the fuel fabrication area since the program may have to produce the early (prototypical) fuel in a laboratory. Testing such fuel without a pedigree (i.e., fuel fabricated under a QA/QC program that is neither NRC-approved or licensee-approved) will likely be of little benefit to the licensing process.

\subsection{LICENSING APPROACH}

The "Gallium Issues" paper undertook the task of focusing on licensing issues that were of direct importance to the Gallium-Clad task and MOX in general. Licensing of fuel elements based on weapons grade (WG) MOX will emphasize points of departure from previously used fuel designs, which are: (1) different isotopics of WG plutonium; (2) different morphology of the $\mathrm{PuO}_{2}$ powder; and (3) the presence of impurities in plutonium, principally gallium. In addition there is the broader question of using MOX fuel after a hiatus of more than a 20 years in the US during which time the licensing process has undergone change. A favorable point is the successful use of MOX in Europe and the industrial base supporting it.

According to 10.CFR.50, licensing WG-MOX fuel calls for an amended Safety Analysis Report (SAR), based on a complete record of supportive data written in a Licensing Topical Report (LTR) (or a series of LTRs). The NRC reviews and approves these documents according to directives in the Standard Review Plan (SRP). Therefore, 10.CFR.50 and the SRP are the two key documents defining the requirements of the test program. Admonitions in the SRP ask that NRC reviewers focus on points of departure from previous designs. Therefore, one can expect that gallium will be one of the main NRC issues in the fuel design area.

In addition, 10.CFR.50 dictates that a Probabilistic Risk Assessment (PRA) is required for new applicants (i.e., as of February 1982). Interpretation of this section (the Post TMI Requirements section) by. licensing experts reached the consensus that at some point the applicant will be asked if the new fuel will alter the PRA. Obviously it would be highly desirable to the program if the answer were unequivocally no.

Summarizing from these sources, a test program must address the following four points:

(1) A design limit must be established for gallium concentration below which the cladding will not be damaged by its presence for all expected irradiation conditions. The SRP and General Design Criterion (GDC) 10 state that the design limit must include an appropriate safety margin.

Comment: By NRC definition, non-damage to cladding signifies no dimensional change beyond design limits, no interior corrosion beyond that expected for LEU fuel, no loss of ductility or strength beyond that expected for LEU fuel, and no loss of hermeticity. In addition, fuel rod failure can be an economic penalty for the utility and economic considerations may be as demanding as safety ones. Current LEU fuel rod failures are in the range of 1 part in $10^{5}$.

(2) It is highly desirable, though not absolutely essential, that the mechanism for potential damage by gallium to Zircaloy be understood. 
Comment: This is a strong recommendation in the SRP. Also, a good understanding of the damage mechanism, together with other successful program elements may permit acceleration of fuel insertion into the reactor.

(3) It must be assured that current methods do not underestimate radioactivity available for release during a Design Basis Accident (DBA).

Comment: This includes the circulating activity and the gap inventory. The SRP requires that the gap inventory is not underestimated by current methods and that increases in circulating inventory due to cladding failures be accounted for. In addition, acceptable fuel fission gas release may be impacted by this requirement.

(4) It must be assured that neither the probability nor the source term for a severe accident is increased beyond predictions by current methods through use of WG-MOX fuel.

Comment: The principal item is demonstrating that fission product release from overheated $W G-$ MOX fuel during a severe accident is not underestimated. A second item is demonstrating that the number of fuel rod failures is not underestimated during a severe accident. The latter may be proven by demonstrating that Zircaloy ductility loss, strength loss, and interior corrosion are not higher than expected from $L E U$ fuel experience.

Note that, in general, items 3 and 4 impact the use of MOX fuel whether or not gallium is involved. It was felt that the Gallium-Clad Phases I through IV along with the irradiation testing could provide information for normal operation (items 1 and 2), but would be insufficient for DBAs and as information for reviewing the PRA. 


\subsection{PLANNING FOR GALLIUM-CLAD FUTURE TASKS}

Because the "Gallium Issue" report identified accident and normal operations concerns, a minor task was undertaken to review some of the literature on fuel and clad testing at the temperature region above $1000^{\circ} \mathrm{C}$ and determine if any tests could be incorporated into the existing program at low cost. Considerable work has been done on fuel and clad behavior during accident conditions and to duplicate these experiments with gallium would be very time consuming and expensive. In addition, the gallium could affect the fuel microstructure and change gas release behavior, launching yet another expensive and time consuming fuel effort. Results to date do not appear to justify this extensive level of testing for trace gallium levels; however, no long term tests under actual reactor conditions with production quality fuel have been completed that could be used to quell utility and regulatory concerns.

Broadly speaking, the extended testing would fall into three categories: 1) Burst tests, where the fuel rod internal pressure is greater than the external pressure and the clad "balloons" under test conditions; 2) power cooling mismatch testing, where the fuel rod internal pressure is less than the extemal pressure and the clad is collapsed onto the fuel; and 3) severe accidents, where fuel and clad melting occur. Item 3 was considered to be outside the scope of the review. It could be required even with gallium free fuel if the MOX database has shortcomings because of the melting point differences between MOX and LEU fuel. At present, it is considered to be a long term concern that will have to be addressed by the selected consortium.

\subsection{LOSS OF COOLANT ACCIDENTS}

The main event in this temperature/pressure regime is a loss of coolant accident (LOCA), and the two major questions to be answered are (1) How long will the fuel rods survive at this temperature before they balloon, burst, or otherwise fail and (2) If the fuel rods are quenched with water after rising to high temperature for a short time, will they have become so brittle that failure by thermal shock is likely? One effect of gallium that needs to be evaluated is the extent that clad damage is significantly accelerated over the short time span of the event (minutes to hours). The main question is if trace amounts of gallium will increase the fission product release from fuel rods under LOCA conditions either by direct influence or by affecting other reactions. Long term effects are not of interest because the core would be scrapped after a LOCA.

The major concern lies in the change of clad properties due to (1) oxidation and oxygen uptake from both the steam and the fuel, and (2) temperature. This behavior is illustrated in Figure 4. In the temperature range of concern, the clad will react with both the steam in the reactor vessel and the uranium dioxide fuel. The clad will react with the steam to form an oxide and the clad will begin to react with the fuel to form a multi component $\mathrm{Zr}$-U-O system. In addition, the zirconium undergoes a phase transition first from alpha to beta phase, due to temperature, and then back to alpha phase as the oxygen content increases. This whole process attacks the integrity of the clad by consuming the clad material due to chemical reactions and embrittling the remaining clad material by oxygenation. The NRC has embodied this complex behavior in its $17 \%$ equivalent cladding reacted rule. Also, as the temperature rises the clad strength will drop and the fuel rod may begin to balloon or collapse due to the pressure differential between the fuel rod and the reactor volume.

Numerous experiments have been conducted to study this behavior at various heating rates and environments. How one would study the addition of gallium to this system in an economical manner is not clear. First, one would have to determine how fast the gallium moves into the clad at $1000^{\circ} \mathrm{C}$. Unless the clad has been perforated, the steam reaction takes place on the outside of the clad and will not be 
affected by the gallium (if trace gallium even has an effect) unless the gallium rapidly moves into the bulk material at elevated temperatures. It seems unlikely that trace amounts of gallium would influence oxidation behavior, phase transitions, or diffuse at high speed, but these issues may have to be at least looked at in some way to satisfy utility and NRC concerns.

Clad internal oxidation effects are the most plausible for gallium. The likely focus would be on the $\mathrm{UO}_{2}$ $+\mathrm{Zr}$ reaction and whether gallium has any effect on this reaction. This reaction is just beginning at about $1000^{\circ} \mathrm{C}$ and is affected to some extent by the $\mathrm{ZrO}_{2}$ layer likely to be found on the inside of the clad. The literature indicates that tests performed with the fission products $\mathrm{Cs}, \mathrm{I}$, and Te did not exert a major influence on the $\mathrm{UO}_{2}+\mathrm{Zr}$ reaction, so trace elements may not be important. However, solid contact between the fuel and clad is important for the reaction to occur. This should be considered when designing an experiment. 


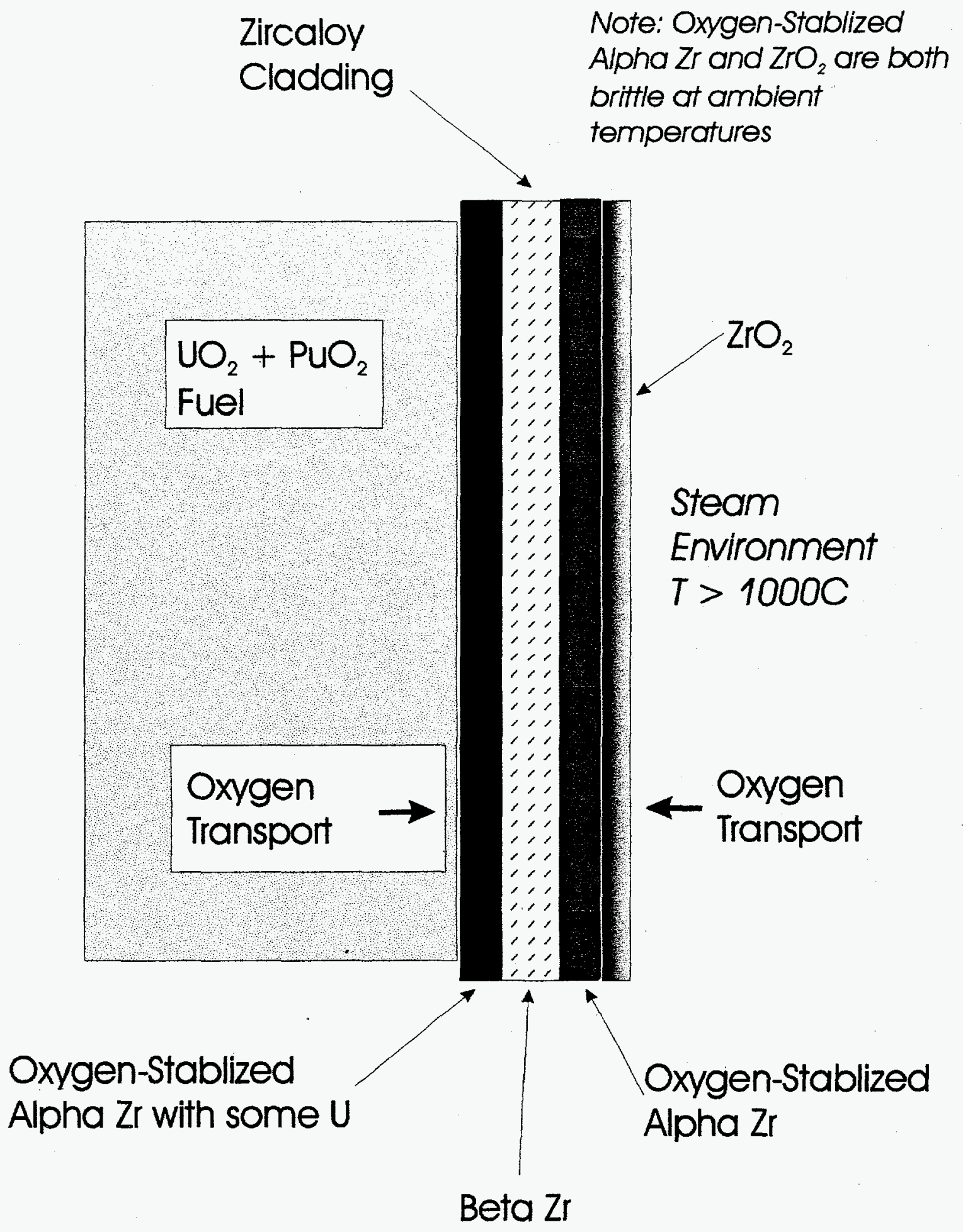

Figure 4. Zircaloy steam and fuel reactions that occur under LOCA conditions. 


\subsection{LESSONS LEARNED}

In the end, the Gallium-Clad Phase III and IV efforts were overcome by technical problems and planning risks that were not fully understood or apparent at the onset. In retrospect, the effort had three separate challenging technical areas:

1. The design of the test apparatus and rodlet. The design and control of the heating and heat removal system was a significant engineering effort that deserved a more formal approach, more testing, and greater documentation. The task depended too heavily on previous work done by another project.

2. The fabrication of the annular pellets. The project was well along and the funds nearly exhausted when it was determined that the desired test articles could not be made with the planned approach. More time and resources should have been included for a development effort.

3. Gallium detection. The desired outcome of the experiment was to map the gallium migration and determine what effect it might have. It was hoped that gallium detection methods would mature during the course of the task, but this did not happen and the fallback techniques, while sensitive, would have been tedious to use for mapping applications.

Above and beyond the technical issues was a programmatic issue. The work on the Gallium-Clad task began without allowing the necessary time to develop a clear focus on the final result because of the schedule driven nature of the FMDP effort. As the task evolved, the real goal of the effort became apparent, which was to support an effort to get the fuel material accepted and licensed. The work on licensing did not begin until the Spring of 1998, too late to really influence the task before the consortium selection. Doing this work earlier would have provided a firmer planning base for the task and would have tied it in more directly with the FMDP goals.

A positive outcome of the task was the result that sintered pellets are unlikely to have gallium concentrations of more than a few ppm and that a practical licensing approach is possible and that its basic form has been identified. 


\subsection{BIBLIOGRAPHY}

1. J. Belle, Uranium Dioxide: Properties and Nuclear Applications, United States Atomic Energy Commission, 1961.

2. H.M. Chung, A.M. Garde, and T.F. Kassner, High-Temperature Deformation and Rupture Behavior of Internally-Pressurized Zircaloy-4 Cladding in Vacuum and Steam Environments, CONF-770708-16.

3. B.S. Cowell, Technical Specification: Mixed-Oxide Pellets for the Light Water Reactor Irradiation Demonstration Test, ORNL/MD/LTR-72, June 1997.

4. B.S. Cowell, S.A. Hodge, Fissile Materials Disposition Program Light Water Reactor Mixed Oxide Fuel Irradiation Test project Plan, ORNL/MD/LTR-78.

5. A.W. Cronenberg, M.S. El-Genk, An Assessment of Oxygen Diffusion During $\mathrm{UO}_{2}$ Zircaloy Interaction, TREE-NUREG-1192, Jan 1978.

6. A.W. Cronenberg, In-Vessel Zircaloy Oxidation/Hydrogen Generation Behavior During Severe Accidents, NUREG/CR-5597, Sept 1990.

7. C.C. Dollins, M. Jursich, A Model for the Oxidation of Zirconium-Base Alloys, WAPD-TM- 1495, May 1981.

8. Fuel-Coolant Interactions, ASME, HTD-Vol 19, 1981.

9. J.H. Gittus, J.R. Matthews, and P.E. Potter, Safety Aspects of Fuel Behavior During Faults and Accidents in Pressurized Water Reactors and in Liquid Sodium Cooled Fast Breeder Reactors, J. Nucl. Mater. 166 (1989) 132-159.

10. P. Hofmann, C. Politis, Investigations of the Influence of Oxide Fuel and Fission Products on the Mechanical Properties of Zry-4 Cladding Tubes Under LWR Transient Conditions, Proceedings of the Topical Meeting on Thermal Reactor Safety, July 31-Aug 4, 1977, Sun Valley Idaho, CONF-770708.

11. Terrence B. Lindemer, Assessment of Gallium in (U, Pu) $\mathrm{O}_{2}$ LWR Fuels, July 29, 1995.

12. D.H. Locke, The Behaviour of Defective Reactor Fuel, Nucl Eng.and Design, 21 (1972) 316-330.

13. R.N. Morris, C.A. Baldwin, D.F. Wilson, Gallium-Cladding Compatibility Testing Plan Phase III : Test Plan for Centrally Heated Surrogate Rodlet Test, ORNL/MD/TR-146, July 1998.

14. P.L. Rittenhouse, Progress in Zircaloy Cladding Failure Modes Research, ORNL-TM-3188, Dec 1970.

15. P.L. Rittenhouse, Failure Modes of Zircaloy-Clad Fuel Rods, ORNL-TM-2347, Sept 1968.

16. P.L. Rittenhouse, Failure Modes of Zircaloy-Clad Fuel Rods Part 2: Program Revisions, ORNL-TM2548, May 1969.

17. P.L. Rittenhouse, Failure Modes of Zircaloy-Clad Fuel Rods, Part 3: Description of the ORNL Program, ORNL-TM-2742, Jan 1970.

18. J.B. Rivard, The Relationships and Influences of Fuel and Coolant System Processes During LWR Severe Accidents, NUREG/CR-4320, Dec 1986.

19. S.L. Seiffert, R.R. Hobbins, Oxidation and Embrittlement of Zircaloy-4 Cladding from High Temperature Film Boiling Operation, NUREG/CR-0517, April 1979.

20. H. Steiner, M. Heck, Stresses in an Oxidized Zircaloy Cladding Under Quench Conditions: Recalculation of Single-Rod Quench Tests, Nucl Tech., 123 (1998), 209-221.

21. R.P. Wichner, R.N. Morris, Gallium Strategy, ORNLTM-13667, July 1998.

22. R.E. Williford, An Assessment of Safety Margins in Zircaloy Oxidation and Embrittlement Criteria for ECCS Acceptance, NUREG/CR-4412, April 1986

23. D.F. Wilson, R.N. Morris, Gallium-Cladding Compatibility Testing Plan Phases I and II: Test Plan for Gallium Corrosion Tests, ORNL/MD/LTR-133, May 1998.

24. D F. Wilson, et. al., Potential Effects of Gallium on Cladding Materials, ORNLTM-13504, Oct 1997.

25. D.F. Wilson, et. al., Interactions of Zircaloy Cladding with Gallium 1997 Status, ORNL/TM- 13505, Nov 1997.

26. D.F. Wilson, et. al. Interaction of Zircaloy Cladding with Gallium: 1998 MidYear Status, ORNL/TM13625, June 1998. 


\subsection{DISTRIBUTION}

1. Howard Canter, U.S. Department of Energy, MD-3, 1000 Independence Avenue SW, Forrestal Building 6G-050, Washington DC 20585

2. Dave Nulton, U.S. Department of Energy, MD-3, 1000 Independence Avenue SW, Forrestal Building 6G-050, Washington DC 20585

3. P.T. Rhoads, U.S. Department of Energy, MD-3, 1000 Independence Avenue SW, Forrestal Building 6G-050, Washington DC 20585

4. J. Thompson, U.S. Department of Energy, MD-3, 1000 Independence Avenue SW, Forrestal Building 6G-050, Washington DC 20585

5. Jami Johnson, U.S. Department of Energy, MD-3, 1000 Independence Avenue SW, Forrestal Building 6G-050, Washington DC 20585

6. Damian Peko, U.S. Department of Energy, MD-3, 1000 Independence Avenue SW, Forrestal Building 6G-050, Washington DC 20585

7-11. D. Alberstein, Los Alamos National Laboratory, P.O. Box 1663, Los Alamos, NM 87545

12-16. S. O'Kelly, Nuclear Science Center, Texas A \& M University, College Station, TX 778433575

17. R. Hanranhan, LANL, Los Alamos National Laboratory, P.O. Box 1663, Los Alamos, NM 87545

18. Darryl Butt, LANL, Los Alamos National Laboratory, P.O. Box 1663, Los Alamos, NM 87545

19-20. OSTI, P.O. Box 62, Oak Ridge, TN 37831

21. C. A. Baldwin

22. R.L. Beatty

23. B.B. Bevar

24. B.S. Cowell

25. J.R. DiStefano

26. S.A. Hodge

27. L.J. Ott

28-30. R.N. Morris

31. D.L. Moses

32. D.G. O'Connor

33. S.R. Greene

34. R.P. Wichner

35. D.F. Wilson

36. ORNL Laboratory Records (RC) 